\title{
Gaceta Médica de México es la memoria de la medicina y los médicos de México
}

Francisco Espinosa-Larrañaga*

Gaceta Médica de México, Ciudad de México, México

...el dios egipcio Theuth, inventor de los números y del cálculo, de la geometría y de la astronomía, de los juegos de dados y de mesa y, por fin, de la escritura, expone estas invenciones suyas al rey de Tebas y de todo Egipto para que este las haga difundir entre todos los egipcios. El rey quiere saber la finalidad y las ventajas de estas cosas; el último de esos inventos es la escritura. "Esa ciencia, oh rey -dice Theuth- hará a los egipcios más sabios y de mejor memoria: se ha hallado el fármaco de la memoria y de la sabiduría.

Pero él le dijo: ¡Oh, artificioso Theuth! por que es olvido lo que producirán en las almas de quien la aprenda, al descuidar la memoria, ya que fiándose de lo escrito, llegarán al recuerdo desde fuera, a través de caracteres ajenos, no desde dentro, desde ellos mismos y por sí mismos.

Fedro. Platón Pasaje (247c-275b) $)^{1}$

Haber desarrollado un lenguaje articulado fue un gran avance para la humanidad. La creación de un sistema de escritura y su lectura permitió el desarrollo de la memoria colectiva, la conciencia social, la interpretación de emociones y, finalmente, la creatividad como una evidencia de madurez intelectual.

La escritura dio lugar al documento y, posteriormente, al libro, cuyo origen se considera se remonta a más de 5 mil años, así como también al sujeto que escribía y al sujeto para quién se escribía. , $^{2,3}$

Desde la antigüedad, el valor de un libro pareció estar dentro del mismo objeto, ya que en un inicio se comercializó y reprodujo manual o artesanalmente hasta el descubrimiento de la imprenta. El resguardo de los libros en bibliotecas o espacios religiosos como los monasterios es una muestra del valor que le concedía la sociedad a la escritura, al documento, al escribiente, a la información y a quien poseía los libros o tenía la capacidad para leer y escribir. ${ }^{4,5}$
A través de los libros y la escritura se llevó a cabo la transmisión del conocimiento, la cosmovisión e interpretación de las culturas, pero al mismo tiempo de ciencias como las matemáticas, la geometría, la astronomía e, incluso, el arte de curar. Desde la antigüedad, el libro se ha considerado un depositario de conocimientos y un instrumento educativo. ${ }^{3,6}$ El establecimiento de un método y su sistematización para crear conocimiento, hoy conocido como método científico, incrementó la velocidad de descubrimiento.

La popularidad y el desarrollo de los tipos y la linotipia, amén de la fundación de varias imprentas en diversos países, permitieron imprimir con mayor facilidad y dieron lugar al desarrollo de otro tipo de publicación diferente al libro, basado en el concepto del periódico. ${ }^{5}$

En la primera mitad del siglo XVIII, la divulgación del conocimiento científico estrenó un nuevo formato: la revista médica, con la fundación del Medical Assays and Observations, en 1733, que a la postre se convertiría en Scottish Medical Journal. Por su parte, desde sus inicios en 1812, New England Journal of Medicine tuvo como objetivo el intercambio de experiencias entre los profesionales, en un ambiente dispuesto para la investigación y la reflexión. En 1823 apareció The Lancet; en 1843, The Journal of the American Medical Association (JAMA), y en 1857, The British Medical Journal. En México, siete años después, en 1864, surgió Gaceta Médica de México, antes que la decana de las revistas francesas, La Presse Médicale, que vio la luz casi 30 años después, en $1893{ }^{6}$

Actualmente con internet y el desarrollo de las tecnologías de la información y comunicación (TIC)
Gac Med Mex. 2019;155:333-335

Disponible en PubMed www.gacetamedicademexico.com 
estamos viviendo un cambio de modelo de las revistas médicas: en algunos casos coexisten los formatos impreso y electrónico; en otros, la publicación ha migrado totalmente a este nuevo soporte, incluso, algunas "nacen" siendo electrónicas. A pesar de ello, escribir un documento científico y la escritura persisten como arquetipo de la comunicación gráfica humana.

Aplicadas a la divulgación del conocimiento, las TIC han permitido el desarrollo de sistemas que hacen posible acortar los tiempos de edición y publicación. También han facilitado el manejo de documentos, el envío, resguardo (bibliotecas virtuales), procesamiento y distribución de los contenidos; la divulgación del conocimiento se realiza prácticamente al terminar de procesar un documento.? Los formatos electrónicos han incrementado de manera importante la visibilidad de la publicación, con lo cual el número de usuarios puede crecer de manera considerable sin que sea necesario aumentar el presupuesto. Al respecto, es necesario considerar que existen publicaciones en formato electrónico de acceso abierto y otras limitadas a un pago de derechos.

Gaceta Médica de México ha evolucionado paulatinamente: de lo impreso a un formato dual, impreso y electrónico, y a partir del número 2 del volumen 155 de 2019 al exclusivamente electrónico de acceso abierto y en modalidad bilingüe, dado que todos los artículos se publican íntegros en inglés y español. ${ }^{8}$

Durante casi tres siglos, las revistas médicas han constituido parte de la "memoria colectiva" de los médicos y la medicina. El incremento de la producción de documentos científicos médicos es un estado acorde con los tiempos de la tecnología. Espero que en su modalidad electrónica se mantengan como el reservorio de la historia de esta disciplina. Innegablemente, la palabra espero entraña esperanza y al mismo tiempo duda.

¿De dónde el origen de la duda? Explico. En una publicación reciente sobre aspectos históricos relacionados con Gaceta Médica de México se presenta el listado de editores y coeditores de la misma de 1864 a 2018. Me llamó la atención que para el periodo de 1968 a 1994 solo se registraron los editores, ${ }^{9}$ lo cual supuse que podía atribuirse a una política editorial establecida en ese entonces entre editores y las mesas directivas de la Academia Nacional de Medicina de México. Para corroborarlo me di a la tarea de consultar las fuentes primarias, es decir, los números impresos de Gaceta Médica de México de esos años en la biblioteca de la propia Academia. Para mi
Tabla 1. Editores, coeditores y responsables de la edición de Gaceta Médica de México durante el periodo de 1969 a 1994*

\begin{tabular}{|c|c|c|c|}
\hline Año & Editor & Coeditor (es) & $\begin{array}{l}\text { Responsable } \\
\text { de edición }\end{array}$ \\
\hline 1968-1969 & Silvestre Frenk & & \\
\hline 1970-1971 & Silvestre Frenk & $\begin{array}{l}\text { Rubén Argüero } \\
\text { Sánchez }\end{array}$ & \\
\hline $1972-1974$ & Silvestre Frenk & & $\begin{array}{l}\text { Alejandro } \\
\text { Somolinos }\end{array}$ \\
\hline 1975-1977 & Manuel Quijano & & $\begin{array}{l}\text { Alejandro } \\
\text { Somolinos }\end{array}$ \\
\hline 1978-1980 & Silvestre Frenk & $\begin{array}{l}\text { Juan Somolinos } \\
\text { Palencia }\end{array}$ & \\
\hline 1981-1983 & Silvestre Frenk & & $\begin{array}{l}\text { Alejandro } \\
\text { Somolinos }\end{array}$ \\
\hline 1984-1985 & $\begin{array}{l}\text { Juan Somolinos } \\
\text { Palencia }\end{array}$ & $\begin{array}{l}\text { Sergio Ponce de } \\
\text { León }^{1}\end{array}$ & $\begin{array}{l}\text { Alejandro } \\
\text { Somolinos }\end{array}$ \\
\hline 1985-1987 & $\begin{array}{l}\text { Juan Somolinos } \\
\text { Palencia }\end{array}$ & & $\begin{array}{l}\text { Alejandro } \\
\text { Somolinos }\end{array}$ \\
\hline 1988-1989 & Arturo Zárate & $\begin{array}{l}\text { Salvador } \\
\text { Villalpando² }\end{array}$ & $\begin{array}{l}\text { Alejandro } \\
\text { Somolinos }\end{array}$ \\
\hline 1990-1992 & $\begin{array}{l}\text { Juan Somolinos } \\
\text { Palencia }\end{array}$ & $\begin{array}{l}\text { Silvestre Frenk } \\
\text { Daniel } \\
\text { Vasconcelos }\end{array}$ & \\
\hline 1993-1994 & $\begin{array}{l}\text { Héctor Pérez } \\
\text { Rincón }\end{array}$ & $\begin{array}{l}\text { Alejandro } \\
\text { Treviño Becerra } \\
\text { Pelayo Vilar Puig }\end{array}$ & $\begin{array}{l}\text { Juan Domingo } \\
\text { Argüelles }^{5}\end{array}$ \\
\hline \multicolumn{4}{|c|}{$\begin{array}{l}\text { *Fuente: Página legal de cada uno de los números de Gaceta Médica de México del } \\
\text { volumen } 104 \text { (1968) al } 130 \text { (1994). } \\
\text { 'Participó como coeditor hasta el número } 3 \text { del volumen } 121 \text { (1985). } \\
{ }^{2} \text { Se incorporó como coeditor en el volumen } 125 \text { (1989). } \\
{ }^{3} \text { Coeditor en el volumen } 126 \text { (1990). } \\
{ }^{4} \text { Coeditor en el volumen } 128 \text { (1992). } \\
{ }^{5} \text { Estuvo a cargo del cuidado de la edición en 1994. Actualmente labora como editor de } \\
\text { la revista de la Universidad lberoamericana y como crítico literario y ensayista para los } \\
\text { diarios Milenio y La Jornada. }\end{array}$} \\
\hline
\end{tabular}

sorpresa no era posible consultar dicha información, porque los ejemplares correspondientes habían sido encuadernados por volumen y habían sido eliminadas la portada y la página legal con los nombres de los editores y coeditores. Recurrí entonces a la colección en formato electrónico del acervo de la revista, la cual fue coordinada por el doctor Emilio García Procel..$^{10} \mathrm{La}$ colección mencionada abarca de 1864 a 2007 y recopila todos los artículos publicados en esos años, ordenados por volumen y número, pero tampoco contiene las portadas ni las páginas legales. Finalmente, decidí acudir al Centro Nacional de Investigación Documental en Salud (CENAIDS), del Instituto Mexicano del Seguro Social, que tiene en resguardo colecciones completas de Gaceta, al igual que la Universidad Nacional Autónoma de México. Aunque Gaceta también 
había sido encuadernada por volumen, en el CENAIDS se mantuvieron las portadas y las páginas legales de cada número, donde se indican los nombres de los editores, coeditores y otros participantes como coordinadores y correctores (Tabla 1).

De lo anterior me parece importante señalar que en la versión electrónica de las revistas se omite información valiosa que forma parte de la memoria histórica de las propias publicaciones.

Desde el segundo semestre de 2017, Gaceta Médica de México tiene su sitio web (www.gacetamedicademexico.com) en la plataforma de la editorial Permanyer, responsable de la edición de la revista, de ahí la pertinencia de preguntar si se está preservando la información acerca de los editores, coeditores y responsables de la edición. La respuesta es no, no se está conservando, lo que nos obliga a corregir, estamos a tiempo.

Por fortuna, el señor Ricard Permanyer, director general de Permanyer, ha mostrado sensibilidad para dar continuidad a las colecciones físicas de la revista en las bibliotecas de la propia Academia y la del Centro Nacional de Investigación Documental en Salud del Instituto Mexicano del Seguro Social.

\section{Conclusiones}

Es responsabilidad de los editores de Gaceta Médica de México mantenerla como memoria histórica de la medicina en México, de los sujetos sociales que escriben y de lo que escriben, sin importar el formato. Para ello debemos estar atentos a que cuando se encuaderne la revista se conserven portadas y páginas legales, gestionar que en el sitio web exista un apartado con las portadas y nombres de editores, coeditores y responsables de la edición y que la información en formato electrónico sea actualizada para su uso en los emergentes sistemas digitales y conservarla con profesionalismo para evitar su deterioro.

\section{Epílogo}

La escritura no sustituyó a la memoria, por el contrario, se convirtió en un sistema que permitió almacenarla. Esperamos que los formatos y reservorios electrónicos sean tan eficientes como lo han sido los impresos y las bibliotecas tradicionales para conservar las fuentes históricas. También es deseable que los cambios tecnológicos que se suceden a una velocidad impresionante no lleven a olvidar la función histórica social de las publicaciones científicas. Confío en que para el 2164 pueda consultarse en forma electrónica todo el acervo de Gaceta Médica de México, cuando esta revista cumpla 300 años de existencia, tal como ha hecho posible el soporte impreso con Medical Assays and Observations.

\section{Bibliografía}

1. Diálogos de Platón. Fedro. Madrid, España: Gredos; 2010. p. 832-834.

2. Viñao-Frago A. Leer y escribir. Historia de dos prácticas culturales. México: Fundación Educación, voces y vuelos, IAP; 1999.

3. Raimondo-Cardona G. Antropología de la escritura. Segunda edición. Barcelona: Gedisa; 1999.

4. Svend D. Historia del libro. México: Consejo Nacional para la Cultura y las Artes/Alianza editorial/Editorial Patria; 1991.

5. De La Torre-Villar E. Elogio y defensa del libro. México: UNAM, Coordinación de Humanidades; 1990.

6. Espinosa-Larrañaga F, Rico-Méndez FG, Becerrill-Ángeles M. Por qué deben escribir los neumólogos. En: Rico-Méndez FG, Romero-López Z, Cisnero-Martínez JA, Ochoa-Vazquez MD. Salud respiratoria. Tópicos selectos. México: Alfil; 2016. p. 907-920

7. Espinosa-Larrañaga F. Publicaciones médicas y tecnologías de la información. Rev Med Mex Seguro Soc. 2013;51(3):244-247.

8. Treviño-Becerra A. Un triángulo de paradojas. Gaceta Médica de México se publicará solo en forma electrónica. Gac Med Mex. 2019;155(39): 219-220.

9. Rodríguez-Pérez ME. Editores de la Gaceta Médica de México, 1864 a 2018. En: Academia Nacional de Medicina. Notas históricas. México: Permanyer-Conacyt; 2018. p. 109-111.

10. Gaceta Médica de México, 1864-2006 [CD producido por Academia Nacional de Medicina y coordinado por Emilio García-Procel]. México: Academia Nacional de Medicina; 2006. 